\title{
Evaluation of crosslinked and non-crosslinked biologic prostheses for abdominal hernia repair
}

\author{
L. E. de Castro Brás · S. Shurey • P. D. Sibbons
}

Received: 20 February 2011 / Accepted: 1 July 2011 / Published online: 31 July 2011

(C) The Author(s) 2011. This article is published with open access at Springerlink.com

\begin{abstract}
Introduction Abdominal wall defects and incisional hernias represent a challenging problem. Currently, several commercially available biologic prostheses are used clinically for hernia repair. We compared the performance and efficacy of two non-crosslinked meshes in ventral hernia repair to two crosslinked prostheses in a rodent model.

Methods Animals were divided into 12 groups (4 matrix types and 3 termination time-points per matrix). A ventral defect was carefully created and overlapped with the biologic prosthesis.

Results Major complications were seroma induction (3 mesh types), implant extrusion (1 mesh type), severe inflammatory and immune responses (non-crosslinked mesh), fibrosis and mineralisation (3 mesh types). After inflammation resolution, 3 of the matrices tested supported hernia healing but with marked tissue and temporal differences. AlloDerm ${ }^{\circledR *}$ and Surgisis Gold ${ }^{\mathrm{TM}}$ showed tissue reactivity with the host and a rapid rate of matrix remodelling. Bard CollaMend ${ }^{\mathrm{TM}^{*}}$ Implant proved to be inept for hernia repair under the conditions tested. Permacol ${ }^{\mathrm{TM}}$ biological implant integration with host tissue increased over time, supporting hernia healing with strength of tissue, and appears to be a safe prosthetic material for ventral hernia repair based on the results of this rodent study.
\end{abstract}

Keywords Hernia - Rat model · Acellular matrix · Crosslinking $\cdot$ AlloDerm $\cdot$ CollaMend $\cdot$ Permacol . Surgisis gold $\cdot$ SIS

L. E. de Castro Brás $(\bowtie) \cdot$ S. Shurey · P. D. Sibbons

Department of Surgical Research, Northwick Park Institute

for Medical Research, Harrow HA1 1UJ, UK

e-mail: lisandrabras@gmail.com

\section{Introduction}

Abdominal wall defects caused by trauma, incisional hernias and tumour resection are a common and challenging problem for surgeons. The risk of developing an incisional hernia after a midline laparotomy is up to $11 \%$ [1]. The size of the abdominal wall defect and the potential presence of contamination of the site can complicate this commonly performed surgical repair. Several methods are available for abdominal wall defect repair. Primary closure is used widely but in cases of large defects adequate tissue for direct closure may not be available and most surgeons agree that in such cases the defect should be repaired in a tension-free manner using a prosthetic mesh material [2]. Several synthetic and biologically derived materials have been used clinically to repair abdominal hernias. Nonabsorbable synthetic materials are commonly employed, polypropylene mesh being the most used [3,4]. Although these meshes increase abdominal wall strength by mechanical tension [5], mesh contraction and other serious complications such as adhesions, fistula formation, skin erosion and increased susceptibility to infection can result [6]. In addition, subsequent mesh extraction can be difficult due to dense tissue incorporation. Therefore, the use of non-absorbable synthetic meshes in contaminated fields has been strongly discouraged on the basis of high rates of morbidity [7, 8]. Absorbable meshes have also been used for abdominal hernia repair, including synthetic and natural materials. Biological prostheses are derived from bovine, porcine and human sources. These are typically collagenbased and treated to remove cellular elements; some biomaterials are crosslinked additionally to delay the degradation of the collagen by collagenases [9].

The purpose of the study reported here was to compare and evaluate Permacol ${ }^{\mathrm{TM}}$ biological implant (Covidien, 
Dublin, Ireland) with other biologic prosthetic biomaterials, all commercially available and recommended for repair of abdominal wall defects, in a rat model. Permacol ${ }^{\mathrm{TM}}$ biological implant is a dermal collagen porcine-derived biomaterial. Fat deposits, hair follicles, sweat glands and cells are removed during the manufacturer's process, deriving an acellular sheet of collagen and its constituent elastic fibres, with both proteins maintaining their original three-dimensional (3D) structure [10]. To improve durability, Permacol ${ }^{\mathrm{TM}}$ biological implant is stabilised chemically by crosslinking with hexamethylene diisocyanate (HMDI) $[11,12]$. Permacol ${ }^{\mathrm{TM}}$ is a crosslinked bioprosthesis currently in clinical use for hernia repair [13-16].

The study was designed to include both crosslinked and non-crosslinked meshes. A literature research (Pubmed) was performed to identify the bioprosthesis most commonly used for abdominal wall repair. AlloDerm ${ }^{\circledR *}$ Regenerative Tissue Matrix ${ }^{\mathrm{TM}}$ (LifeCell, Branchburg, NJ) is an acellular dermal matrix derived from donated human skin and classified as banked human tissue. It is treated to remove both the epidermis and cellular components while maintaining an intact basement membrane and collagen. AlloDerm ${ }^{\circledR *}$ has been commonly used for ventral hernia repair [17-20], but several cases of post-surgical complications have been reported [18, 21]. Surgisis Gold ${ }^{\mathrm{TM}}$ (Cook Medical, Bloomington, IN) is a porcine-derived small intestinal submucosa (SIS) matrix that is processed to remove all cells. The natural composition of SIS is retained and the matrix is constituted by collagen, glycosaminoglycans, proteoglycans and glycoproteins. Surgisis has been evaluated extensively in animal models [22-24] and used clinically in several surgical procedures, including abdominal hernia repair [25-27]. At the time the study was designed, from the crosslinked biomaterials commercially available, Bard CollaMend $^{\mathrm{TM}_{*}}$ Implant (Davol, Cranston, RI) showed the features closest to Permacol ${ }^{\mathrm{TM}}$ and therefore, to minimize the variables evaluated (same biological source), was chosen as the second crosslinked implant. CollaMend ${ }^{\mathrm{TM}} *$ is a porous lyophilised acellular porcine dermal collagen matrix. It is processed to remove all non-collagenous cellular components and is crosslinked with 1-ethyl-3-[3dimethylaminopropyl]carbodiimide hydrochloride (EDC) to increase strength and endurance. CollaMend ${ }^{\mathrm{TM}} *$ is currently in clinical use for hernia repair $[14,28]$.

\section{Materials and methods}

Animals

This study was performed according to the regulatory guidelines of the UK Home Office. The Home Office Licence governing the studies directly specified the limits of severity of effects on the animals.

Male Sprague-Dawley rats were purchased from Harlan (Blackthorn, UK), allowed to acclimatise for at least 1 week prior to the beginning of the study, and were monitored daily. They were fed a standard rat pellet-chow diet (Special Diet Services, Witham, UK) and tap water ad libitum throughout the study. Animals with weights between 250 and $310 \mathrm{~g}$ were selected. Body weights were recorded on the day of surgery and on the termination day. Animals were distributed randomly within the 12 groups.

\section{Materials}

Dermal matrices were pre-treated according to the manufacturer's instructions. The dermal materials were trimmed aseptically into $5 \times 2.5 \mathrm{~cm}$ implants. Pieces of nonimplanted material were fixed in a $10 \%$ neutral buffered formalin solution (NBF) solution for histological analysis.

Study design

Four treatment groups were constructed for each time point. This resulted in a total of 81 animals for the complete study (Table 1).

\section{Surgical procedure}

Rats were induced and maintained under general anaesthesia. A ventral midline incision was made from just below the level of the rib cage, extending approximately $1.5 \mathrm{~cm}$ distally. Skin was elevated and retracted to allow access to a site at the mid-lateral aspect of the caudal peritoneal wall. Using a template, a $3 \times 0.5 \mathrm{~cm}$ piece of peritoneal wall was excised to leave the peritoneum intact [29]. A piece of biomaterial was placed to cover and overlap the excision equally at each aspect; the implants were secured with absorbable sutures to the peritoneal wall

Table 1 Study groups and time point design

\begin{tabular}{|c|c|c|c|c|c|c|c|c|c|c|c|c|}
\hline \multicolumn{13}{|c|}{ Study groups } \\
\hline Months & 1 & & & & 3 & & & & 6 & & & \\
\hline Group & $\mathrm{A}_{1 \mathrm{M}}$ & $\mathrm{C}_{1 \mathrm{M}}$ & $\mathrm{P}_{1 \mathrm{M}}$ & SIS $_{1 \mathrm{M}}$ & $A_{3 M}$ & $\mathrm{C}_{3 \mathrm{M}}$ & $\mathrm{P}_{3 \mathrm{M}}$ & $\mathrm{SIS}_{3 \mathrm{M}}$ & $\mathrm{A}_{6 \mathrm{M}}$ & $\mathrm{C}_{6 \mathrm{M}}$ & $\mathrm{P}_{6 \mathrm{M}}$ & SIS $_{6 M}$ \\
\hline Animals & 6 & 9 & 6 & 6 & 6 & 9 & 6 & 6 & 6 & 9 & 6 & 6 \\
\hline
\end{tabular}

Biomaterials: $A$ AlloDerm ${ }^{\circledR *}, C$ Bard CollaMend ${ }^{\mathrm{TM} *}$ Implant, $P$ Permacol $^{\mathrm{TM}}$ biological implant, SIS Surgisis Gold ${ }^{\mathrm{TM}}$ 
and non-absorbable sutures were used to identify the corners of the implant. This procedure was performed only on one side of the midline, in half the animals the other side underwent creation of a ventral hernia defect without biomaterial implantation, and was therefore used as a control.

\section{Necropsy}

Animals were euthanased with an intra-peritoneal injection of sodium pentobarbitone, and the operative sites were identified and exposed. The complete operative site together with adjacent tissue was removed; one-third (longitudinally, approximately $4.2 \mathrm{~cm}^{2}$ ) was resected to be used fresh for integration strength testing by way of a tensiometer and the remainder was fixed in $10 \%$ NBF for histopathological analysis. From the opposite, control, side of the animal, a similar-sized piece of peritoneal wall was excised and fixed.

\section{Tensile strength}

In studies where the implant integration with surrounding tissue was tested mechanically, an In-Spec 2200 portable tensiometer (Instron ${ }^{\circledR}$, Bucks, UK) was used. Part of the tissue outside the treatment area was sutured to the movable end of the tensiometer, and the test material sutured to the fixed end of the tensiometer. The movable section of the tensiometer moved away from the fixed end at a constant speed of $0.167 \mathrm{~mm} / \mathrm{s}$ until dissociation occurred either at the test material/tissue junction or in the associated tissues or within the test material.

\section{Histology}

Fixed samples were processed to paraffin wax embedding by routine automated procedures. Two $5 \mu \mathrm{m}$ sections were cut from each wax block in a transverse orientation, one section was stained with haematoxylin and eosin (H\&E) and the other with picro sirius red F3B. H\&E stain was used for general assessment of the tissues and implant, and for identification of cellular type and tissue reaction. Picro sirius red was used to enhance the natural birefringence of collagen. Well conserved and physiologically normal collagen shows bright birefringence using a polarised light microscope whereas denatured or degraded collagen appears black and non-birefringent. Sections were examined for implant presence, acute and chronic inflammation, seroma, fibrosis, giant cells, tissue integration, cellular penetration, cellular density, neo-vascularisation, implant structure retention and collagen degradation. Sections were visualised using an Olympus BX40 microscope (Olympus Optical, London, UK) with a CCD colour Olympus DP70 digital camera. Semi-quantitative analysis included quantification of inflammatory cells, neo-vascularisation and cellular density (non-inflammatory host cells, mainly fibroblasts). A minimum of seven fields per slide were counted at an objective magnification of $40 \times$. Fields were randomly selected within the collagen implant itself and at the interface between the implant and surrounding host tissue. Implant-host tissue integration was measured by analysis of the amount of actual tissue micro-interdigitation (fibroblasts, fibrin, collagen) seen between the edges of the implant and the immediately adjacent host tissue. Integration was measured and scored as a percentage of microinterdigitations observed per area of tissue interface; measurements were performed with ImageJ software (Rasband, ImageJ, US National Institutes of Health, Bethesda, MD). The extent of cellular penetration was quantified (in percentage of the depth of the entire test sample) by measuring minimal and maximal cell penetration per implant thickness (in the same area); a minimum of six randomly selected fields per slide were measured with DP controller software (Olympus Optical), at an objective magnification of $10 \times$. For descriptive purposes, a semi-quantitative histological scoring criterion was generated (Table 2).

\section{Statistical analysis}

Histometric scores were analysed per matrix type and over time using a two-way ANOVA to look for interaction between mesh type and time-point. These tests were performed in conjugation with Levene's test to check for homogeneity of variances; when variances were significantly different, two separate one-way variance analysis were performed instead. One-way ANOVA was also used to analyse the tensiometry results over time. When the ANOVA (one-way and two-way) results were significant, a Bonferroni post hoc test was used to identify differences within groups; when the variances were unequal, Tamhanes's T2 post hoc test was used. $P<0.05$ was considered as statistically significant for all tests applied. Statistical analysis was performed using SPSS Statistics 14.0 (SPSS, Chicago, IL). Data was represented graphically using GraphPad Prism ${ }^{\mathrm{TM}}$ statistics software, version 4 (GraphPad Software, La Jolla, CA).

\section{Results}

During the surgical procedure, CollaMend ${ }^{\mathrm{TM}_{*}}$ was found to be an inflexible, stiff material that was difficult to suture into place. One animal from group $\mathrm{C}_{3 \mathrm{M}}$ and one animal from group $\mathrm{C}_{6 \mathrm{M}}$ died post operatively due to anaesthetic problems. All other animals recovered well from surgery.

Sixteen days post surgery, one animal from group $\mathrm{C}_{3 \mathrm{M}}$ had an open wound lateral to the middle incision caused by 
Table 2 Scoring criteria used for the semi-quantitative histological analysis; units are described per field view

\begin{tabular}{|c|c|c|c|c|c|}
\hline Level criterion & $\begin{array}{l}\text { Absent } \\
0\end{array}$ & $\begin{array}{l}\text { Marginal } \\
1\end{array}$ & $\begin{array}{l}\text { Minimal } \\
2\end{array}$ & $\begin{array}{l}\text { Moderate } \\
3\end{array}$ & $\begin{array}{l}\text { Complete/severe } \\
4\end{array}$ \\
\hline Integration & No integration & $1-25 \%$ integration & $26-50 \%$ integration & $51-75 \%$ integration & $>75 \%$ integration \\
\hline Cellular density ${ }^{\mathrm{a}}$ & No cells & $(1-30)$ cells & $(31-60)$ cells & $(61-90)$ cells & $>90$ cells \\
\hline Cellular penetration & No cells & $1-25 \%$ penetration & $26-50 \%$ penetration & $51-75 \%$ penetration & $>75 \%$ penetration \\
\hline Neo-vascularisation & No vessels & $(1-5)$ vessels & (6-10) vessels & (11-15) vessels & $>15$ vessels \\
\hline $\begin{array}{l}\text { Macrophages and giant } \\
\text { cells }\end{array}$ & No cells & $(1-2)$ cells & $(3-4)$ cells & $(5-6)$ cells & $>6$ cells \\
\hline Mineralisation & $\begin{array}{l}\text { No minerals } \\
\text { present }\end{array}$ & $\begin{array}{l}1-25 \% \text { mineralised } \\
\text { area }\end{array}$ & $\begin{array}{l}26-50 \% \text { mineralised } \\
\text { area }\end{array}$ & $\begin{array}{l}51-75 \% \text { mineralised } \\
\text { area }\end{array}$ & $\begin{array}{l}>75 \% \text { mineralised } \\
\text { area }\end{array}$ \\
\hline
\end{tabular}

${ }^{a}$ Non-inflammatory host cells

Table 3 Tensiometry results for all treatment groups at 1 month post implantation

\begin{tabular}{lllll}
\hline & $\mathrm{A}_{1 \mathrm{M}}$ & $\mathrm{SIS}_{1 \mathrm{M}}$ & $\mathrm{C}_{1 \mathrm{M}}$ & \multicolumn{1}{c}{$\mathrm{P}_{1 \mathrm{M}}$} \\
& $N=6$ & $N=4$ & $N=7$ & $N=6$ \\
\hline Maximum load $(\mathrm{kg})$ & $0.915 \pm 0.194$ & $0.539 \pm 0.238$ & $0.235 \pm 0.103 *$ & $0.730 \pm 0.088$ \\
Extension at max load $(\mathrm{mm})$ & $28.36 \pm 10.42$ & $34.32 \pm 2.638$ & $29.32 \pm 11.91$ & $34.23 \pm 9.806$ \\
Total extension $(\mathrm{mm})$ & $62.55 \pm 15.76$ & $64.02 \pm 25.58$ & $48.96 \pm 18.26$ & $69.81 \pm 8.319$ \\
\hline
\end{tabular}

$* P<0.05$

Table 4 Tensiometry results for all treatment groups at 3 months post implantation

\begin{tabular}{lllll}
\hline & $\mathrm{A}_{3 \mathrm{M}}$ & $\mathrm{SIS}_{3 \mathrm{M}}$ & $\mathrm{C}_{3 \mathrm{M}}$ & \multicolumn{1}{c}{$\mathrm{P}_{3 \mathrm{M}}$} \\
& $N=6$ & $N=2$ & $N=4$ & $0.986 \pm 0.215^{*}$ \\
\hline Maximum load $(\mathrm{kg})$ & $0.592 \pm 0.266$ & $0.568 \pm 0.196$ & $0.476 \pm 0.430$ & $47.65 \pm 4.554$ \\
Extension at max load (mm) & $30.48 \pm 15.62$ & $36.46 \pm 20.09$ & $17.65 \pm 8.859$ \\
Total extension (mm) & $58.50 \pm 17.22$ & $80.16 \pm 27.56$ & $48.17 \pm 2.787$ & $58.79 \pm 18.67$ \\
\hline
\end{tabular}

$* P<0.05$ between crosslinked matrices

friction between the implant and the skin; there was evidence of implant extrusion and the animal had to be sacrificed. Since the implant was detached from the surrounding tissues, tensiometry was not performed in this sample. From 8, 14 and 28 days post implantation it was noted that animals implanted with AlloDerm ${ }^{\circledR *}$, Surgisis Gold $^{\mathrm{TM}}$ (SIS) and CollaMend ${ }^{\mathrm{TM}} *$ were developing seromas. These animals were examined in detail and decisions made as to their continuance in the study. Ten animals from the AlloDerm ${ }^{\circledR *}$ groups showed evidence of seroma $\left(\mathrm{A}_{1 \mathrm{M}} n=4, \mathrm{~A}_{3 \mathrm{M}} n=3\right.$ and $\left.\mathrm{A}_{6 \mathrm{M}} n=3\right)$; all animals were deemed acceptable for continuance in the study under an increased observation regimen. Eight animals implanted with SIS developed seroma, four animals had the seroma drained and were kept in the study, while the other animals had to be sacrificed due to the extent of the seroma (SIS $_{1 \mathrm{M}}$ $n=2, \operatorname{SIS}_{3 \mathrm{M}} n=1$ and $\operatorname{SIS}_{6 \mathrm{M}} n=1$ ). Six animals from the CollaMend ${ }^{\mathrm{TM}_{*}}$ groups were noted to have partially folded implants forming a firm protrusion. These implants did not settle back into the original on-lay position and, as a result, seroma developed between the implant and the peritoneum. Eventually these animals chewed through the skin overlying the implants and this meant the animals had to be terminated prematurely $\left(\mathrm{C}_{1 \mathrm{M}} n=2, \mathrm{C}_{3 \mathrm{M}} n=3\right.$ and $\left.\mathrm{C}_{6 \mathrm{M}} n=1\right)$.

\section{Tensiometry}

Tensiometry was used to study the resistance of the implant/surrounding tissue complex to a constant force applying a separation movement, measured as the maximum tension the material can withstand without integration failure. Tensiometry results are displayed in Tables 3, 4 and 5. Mean and standard deviation were calculated per group and one-way ANOVA used to identify differences between types of matrix. The maximum load sustained by 
Table 5 Tensiometry results for all treatment groups at 6 months post implantation

$* P<0.05$

\begin{tabular}{|c|c|c|c|c|}
\hline & $\begin{array}{l}A_{6 \mathrm{M}} \\
N=4\end{array}$ & $S I S_{6 \mathrm{M}}$ & $\begin{array}{l}C_{6 \mathrm{M}} \\
N=7\end{array}$ & $\begin{array}{l}P_{6 \mathrm{M}} \\
N=6\end{array}$ \\
\hline Maximum load (kg) & $0.821 \pm 0.494$ & - & $0.833 \pm 0.285$ & $1.042 \pm 0.310$ \\
\hline Extension at max load (mm) & $20.02 \pm 6.178$ & - & $30.95 \pm 18.93$ & $30.56 \pm 10.85$ \\
\hline Total extension $(\mathrm{mm})$ & $29.16 \pm 6.95^{*}$ & - & $61.29 \pm 23.69$ & $54.25 \pm 14.68$ \\
\hline
\end{tabular}

the CollaMend ${ }^{\mathrm{TM}_{*}}$ implants was statistically lower than with the AlloDerm ${ }^{\circledR *}$ and Permacol ${ }^{\mathrm{TM}}$ implants at 1 month post implantation. At this time point, no significant difference was observed in the other parameters. At 3 months post implantation, the extension at maximum load was significantly different between the crosslinked matrices $\left(\mathrm{C}_{3 \mathrm{M}}\right.$ and $\left.\mathrm{P}_{3 \mathrm{M}}\right)$. Most SIS $_{6 \mathrm{M}}$ implants had been absorbed at 6 months post implantation; therefore, there was no existing material remaining to test for tensiometry in this group. Total extension values were significantly different for the AlloDerm ${ }^{\circledR *}$ implants at this time point.

It is important to state that stretching of AlloDerm ${ }^{\circledR *}$ was observed for all implants.

\section{Histopathology}

Sections taken from the collagenous prosthetic biomaterials before implantation showed good quality non-denatured collagen in all biological prostheses tested. Cells or cellular fragments were not visible within AlloDerm ${ }^{\circledR *}$, CollaMend $^{\mathrm{TM}_{*}}$ and Permacol ${ }^{\mathrm{TM}}$, although nuclear material was visible in high quantities in SIS (Fig. 1).

Control tissue showed no reactivity to the surgical procedure at all time points assessed. On examination under polarised light, a normal, non-denatured collagen patterning was demonstrated in the controls.

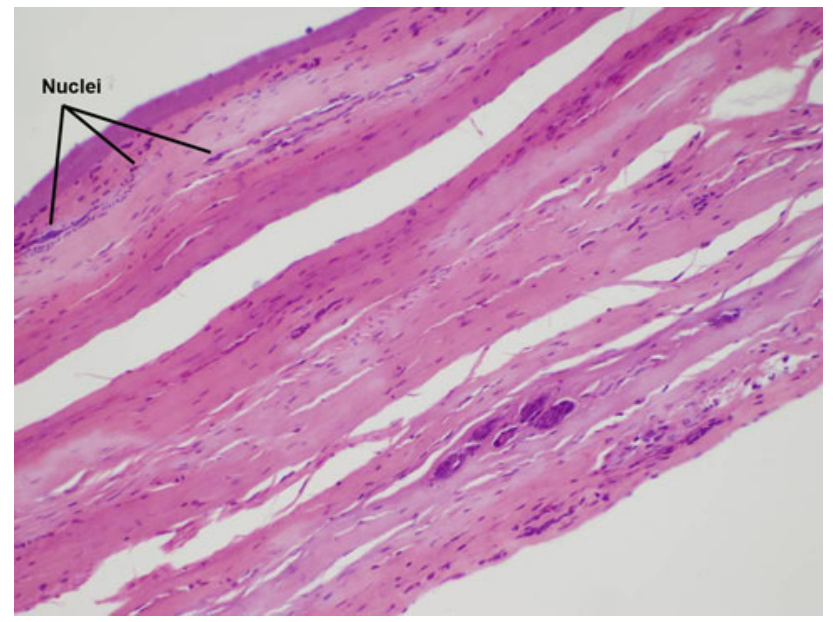

Fig. 1 Non-implanted Surgisis Gold ${ }^{\mathrm{TM}}$ showing high quantities of nuclear material. Nuclear material stains purple and collagen stains pink $(\mathrm{H} \& \mathrm{E}, \times 200)$

\section{One month}

In group $\mathrm{A}_{1 \mathrm{M}}$, two implants showed signs of severe acute and chronic inflammatory responses (Fig. 2a). AlloDerm ${ }^{\circledR *}$ was heavily invaded by inflammatory cells, but in places where the inflammatory response was absent, the implant was cell free. In both implants an inflammatory response was observed between the AlloDerm ${ }^{\circledR *}$ and the abdominal wall. The remaining four implants had moderate levels of acute and chronic inflammatory responses. Lymphocytes, macrophages and polymorphs were present in all implants of this group. In three implants neutrophils were acting as a barrier, surrounding the implant and separating it from the adjacent tissue. Giant cells and fibrotic activity were present in four $\mathrm{A}_{1 \mathrm{M}}$ implants. As observed in the AlloDerm ${ }^{\circledR *}$ implants, SIS showed evidence of severe acute and chronic inflammatory responses, moderate to severe seroma induction, delamination and severe enlargement and activation of local lymph nodes (Fig. 2b). Furthermore, SIS implants were associated with moderate levels of necrosis, fibrosis and mineralisation. The level of inflammation in the non-crosslinked matrices was significantly higher than in the crosslinked matrices $(P<0.001)$.

At 1 month post implantation, Permacol ${ }^{\mathrm{TM}}$ was associated with minimal and marginal levels of acute and chronic inflammatory responses, respectively. The animals from group $\mathrm{C}_{1 \mathrm{M}}$ that were sacrificed prematurely due to seroma development and subsequent open wound formation, showed minimal acute and chronic inflammatory responses; it is not evident if these responses were a result of the seroma or of the open wound. As observed in the AlloDerm ${ }^{\circledR *}$ implants, neutrophils, macrophages and giant cells were visible in $\mathrm{P}_{1 \mathrm{M}}$ implants. The $\mathrm{C}_{1 \mathrm{M}}$ animals that reached the expected end-time point, showed no inflammatory response apart from the presence of low numbers of macrophages. One month post-surgery, the control defects showed no evidence of an inflammatory response; organized collagen deposition was observed within the hernia defect. With time, the extracellular matrix observed in the control tissue became more compact and, at 3 months post implantation, an organized extracellular matrix was observed, although herniation was still present. Finally, at 6 months, it was not possible to distinguish between the healthy tissue and the defect area in the control hernia defects. 

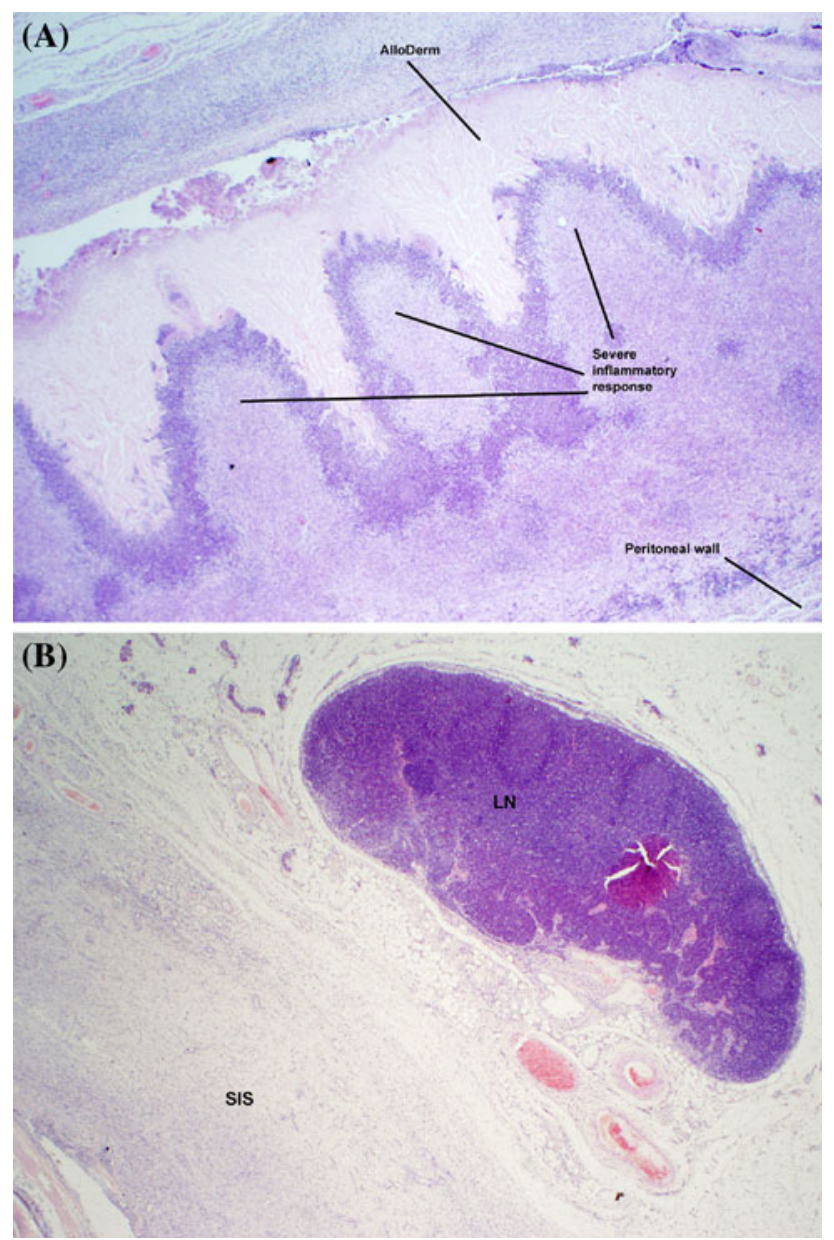

Fig. 2 a AlloDerm ${ }^{\circledR *}$ implant, 1 month post implantation, showing severe acute and chronic inflammatory responses, with inflammatory cells infiltrating the matrix aggressively. b Enlarged lymph node (LN) in the vicinity of a SIS implant, 1 month post implantation. (H\&E, $\times 20$ )

When cellular density was high, blood vessels were visible to support cells. In these places AlloDerm ${ }^{\circledR *}$ and SIS lost their original configuration and were remodelled while implant cell free areas maintained their original structure. Neo-vascularisation was marginal and minimal in the CollaMend $^{\mathrm{TM}} *$ and Permacol ${ }^{\mathrm{TM}}$ implants, respectively.

At the earliest time point, AlloDerm ${ }^{\circledR *}$ lost its natural birefringence, especially at the edges, which indicates collagen degradation; such a result was probably a consequence of the high cellular activity caused by the inflammatory response observed (Fig. 3). This feature was not observed in the other tested matrices.

Integration with the host tissue was high in group $\mathrm{A}_{1 \mathrm{M}}$, especially in the areas where inflammatory cells were predominant. Groups $\mathrm{P}_{1 \mathrm{M}}$ and $\mathrm{SIS}_{1 \mathrm{M}}$ showed minimal levels of tissue integration but CollaMend ${ }^{\mathrm{TM}} *$ implants did not show fibres attaching the implant to the host tissue, except in one aspect where fibrin micro-interdigitations

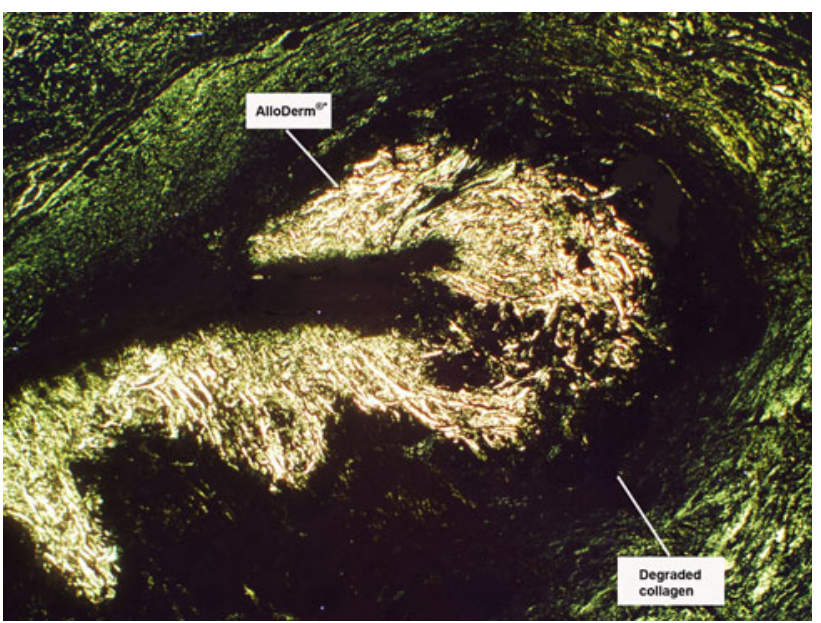

Fig. 3 Degraded collagen in an AlloDerm ${ }^{\circledR *}$ implant, under polarized light (picro sirius red staining $\times 20$ )

were observed between the edge of one implant and the immediately adjacent host tissue.

While the majority of the cells infiltrating groups $A_{1 M}$ and SIS $_{1 \mathrm{M}}$ were leukocytes, fibroblasts were observed in groups $\mathrm{P}_{1 \mathrm{M}}$ and $\mathrm{C}_{1 \mathrm{M}}$ at minimal and marginal levels. It is important to note, however, that, in group $\mathrm{C}_{1 \mathrm{M}}$, fibroblasts were present mainly in the spaces between collagen fibres and not within the fibres. Independent of the level of cellular density, cellular penetration reached $100 \%$ in all matrices.

Three months

Most implants from group $\mathrm{A}_{3 \mathrm{M}}$ showed the remains of marginal to moderate acute and chronic inflammatory response; these responses were significantly different from the values obtained at 1 month post implantation. Because of the inflammatory response, implants were heavily populated with cells and AlloDerm ${ }^{\circledR *}$ configuration changed when a high cellular density was observed. Macrophages were visible in large numbers, especially at the edges of the implants; giant cells were also present but in lower numbers and mature vessels and vessel sprouts were present to support the cellular population. Once more, lymphocytes were visible in excessive numbers indicating a significant immune response. A cellular barrier, constituted mainly by lymphocytes, was visible surrounding the AlloDerm ${ }^{{ }^{\circledR *}}$ implants. Despite the lymphocytic barrier, cellular penetration reached $100 \%$ in all implants and integration with the surrounding tissue was graded as "moderate to complete". Implants with a moderate inflammatory response showed collagen degradation demonstrating implant breakdown.

At 3 months post implantation, SIS implants showed severe acute and chronic inflammatory response and 
delamination (Fig. 4). There remained moderate amounts of seroma, necrosis, fibrosis and mineralisation. Consequently, SIS implants were heavily populated by leukocytes; fibroblasts represented only a smaller fraction of the cell population. There was also continued severe enlargement and activation of local lymph nodes. In contrast to what was observed in group $A_{3 M}$, the elevated cellular density observed did not contribute to increased tissue/ implant integration; tissue integration with the surrounding host tissue was mild.

Only four animals from group $\mathrm{C}_{3 \mathrm{M}}$ reached the protocol experimental final time-point. The implants retrieved from the animals sacrificed prematurely showed evidence of bacterial contamination, most probably as a result of the open wounds. In the presence of bacteria, the CollaMend $^{\mathrm{TM}} *$ matrix was degraded and remodelled. By contrast, the four CollaMend ${ }^{\mathrm{TM} *}$ implants recovered at 3 months post implantation showed no evidence of an inflammatory response, and matrix degradation was not observed. In addition, integration with the adjacent tissue increased to minimal levels, which was significantly different from 1 month post implantation. However, tissue integration was observed mainly within the implant surface facing the subcutaneous tissue and not in the defect area (Fig. 5). Cellular density was minimal and cells were observed fully penetrating the implant, mainly through natural fissures. Macrophages and giant cells were present at the edges of the $\mathrm{C}_{3 \mathrm{M}}$ implants, which is consistent with a foreign body reaction. Consistent with the number of cells observed, vessels were observed in the edges and centre of the implant, although at low levels.

The implants from group $\mathrm{P}_{3 \mathrm{M}}$ showed no evidence of inflammatory or immune responses, which differed

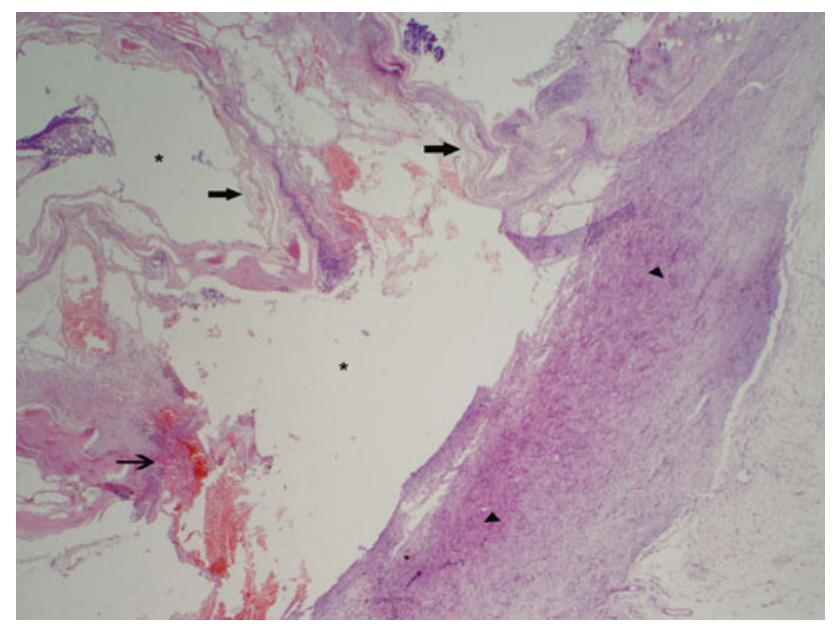

Fig. 4 Implant from group SIS $_{1 \mathrm{M}}$ showing evidence of a severe implant inflammatory response (arrowheads), including delamination of implant (arrows), seroma (asterisks) and tissue necrosis (open head arrows) $(\mathrm{H} \& \mathrm{E}, \times 20)$

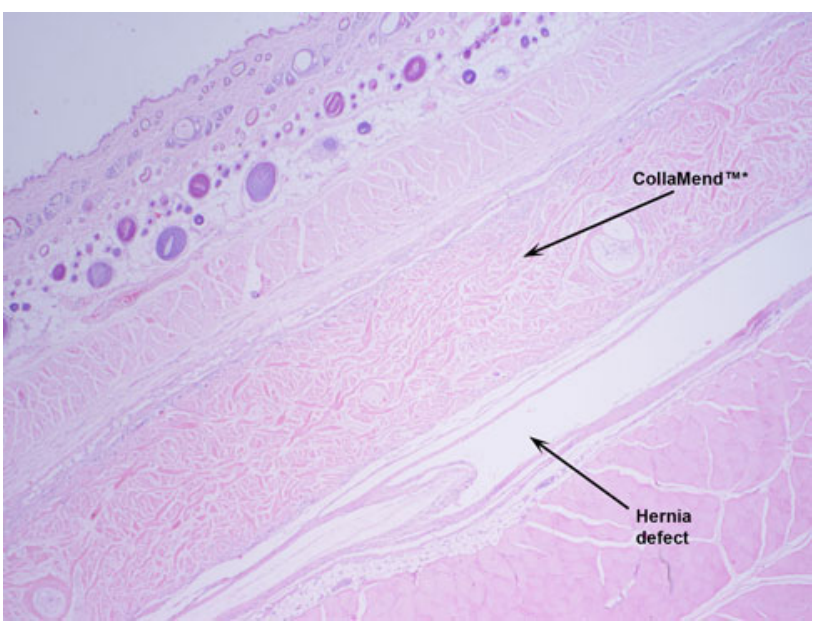

Fig. 5 CollaMend ${ }^{\mathrm{TM}} *$ implant, 3 months post implantation, showing no tissue integration with the hernia defect site $(\mathrm{H} \& \mathrm{E}, \times 20)$

significantly $(P<0.01)$ from group $\mathrm{P}_{1 \mathrm{M}}$. Cellular density was higher than at 1 month, with complete cellular penetration. Fibroblasts were the main cell type present within the Permacol ${ }^{\mathrm{TM}}$ implants (Fig. 6). As a result, tissue integration increased significantly $(P<0.01)$, being moderate to complete at this time point.

\section{Six months}

Two implants from group $\mathrm{A}_{6 \mathrm{M}}$ were absorbed; the other four implants were completely integrated with the surrounding tissue but still identifiable. The inflammatory and immune responses observed at earlier times had resolved and were not observed at 6 months; nevertheless, some macrophagic activity was present and giant cells were observed in one implant, suggesting further remodelling of the matrix. Cellular density increased significantly compared to groups $A_{1 M}$ and $A_{3 M}$, reaching moderate levels, and cellular penetration was $100 \%$ in all AlloDerm ${ }^{\circledR *}$ implants. Neo-vascularisation was present to support the cells. On examination under polarised light, normal, nondenatured collagen patterning was present. Given that at the earlier time points collagen degradation was observed, the normal birefringent collagen patterning observed at 6 months is probably caused by deposition of new collagen, although implants show both mature (thick fibres) and new (thin fibres) collagen.

Like AlloDerm ${ }^{\circledR *}$, SIS implants were partially absorbed and remodelled but, in contrast to AlloDerm ${ }^{\circledR *}$, group SIS $_{6 \mathrm{M}}$ presented levels of acute and chronic inflammatory responses; these parameters differed significantly from the previous time points. Implant delamination was moderate while seroma, necrosis, fibrosis and mineralisation were evident but at mild levels. Tissue integration was significantly higher compared to the previous SIS groups; after 


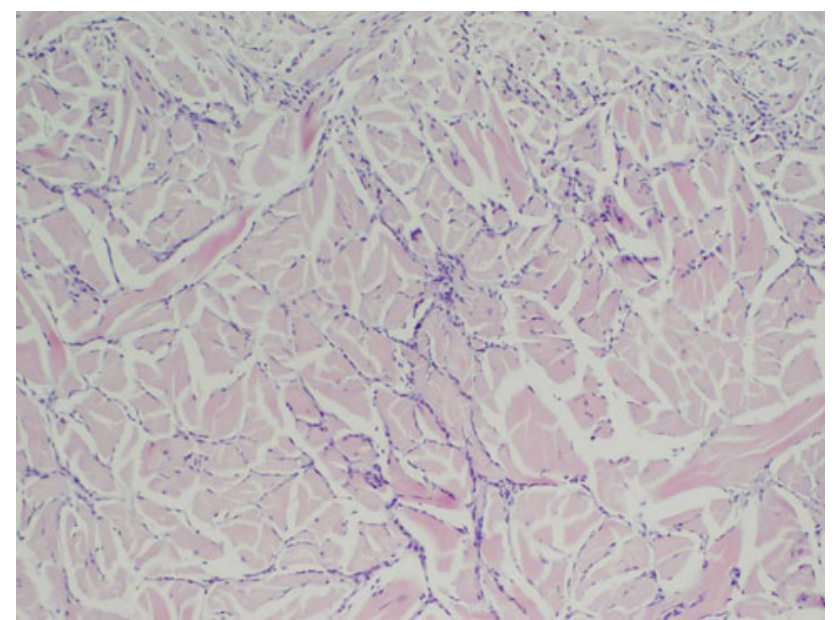

Fig. 6 Permacol $^{\mathrm{TM}}$ implant, group $\mathrm{P}_{3 \mathrm{M}}$, with moderate cellular density and complete cellular penetration $(H \& E, \times 100)$

6 months of implantation, SIS tissue integration with the host tissue was complete.

Both crosslinked implant types showed good quality collagen under polarised light; implant remodelling and degradation were not observed and collagen was naturally birefringent.

Two animals from group $\mathrm{C}_{6 \mathrm{M}}$ showed a small lump externally. In the first animal CollaMend ${ }^{\mathrm{TM}} *$ was folded at one edge and a marginal inflammatory response was present in this area. In the second animal, a fibrotic mass was visible between the implant and the peritoneal wall, demonstrating a marked tissue response to the implant. Among the fibrotic tissue, new collagen was forming and the initial stages of calcification were observed (Fig. 7). Calcification was confirmed with von Kossa's staining.

Group $\mathrm{C}_{6 \mathrm{M}}$ showed low integration with the surrounding tissue; in particular the implant surface facing the peritoneal wall. In some localized areas of the surfaces in contact with the skin, tissue integration reached moderate levels. Independent of the level of tissue integration, cellular density varied from minimal to moderate, and cellular penetration reached $100 \%$ in all implants. To support the cell population, vessel sprouts and mature vessels were observed in high numbers both at the edges and in the centre of the implants. Five implants of group $\mathrm{C}_{6 \mathrm{M}}$ showed minimal-to-moderate numbers of macrophages and giant cells. This occurred more often in the middle of the implant than at the borders. Lymphocytes and plasma cells were also observed, suggesting an immune response. One implant showed a localized chronic inflammatory response, with high numbers of lymphocytes, giant cells and macrophages. In this area, cellular density was complete and integration with surrounding tissue was absent.

Group $\mathrm{P}_{6 \mathrm{M}}$ showed no evidence of inflammatory or immune response. Interestingly, cellular density decreased

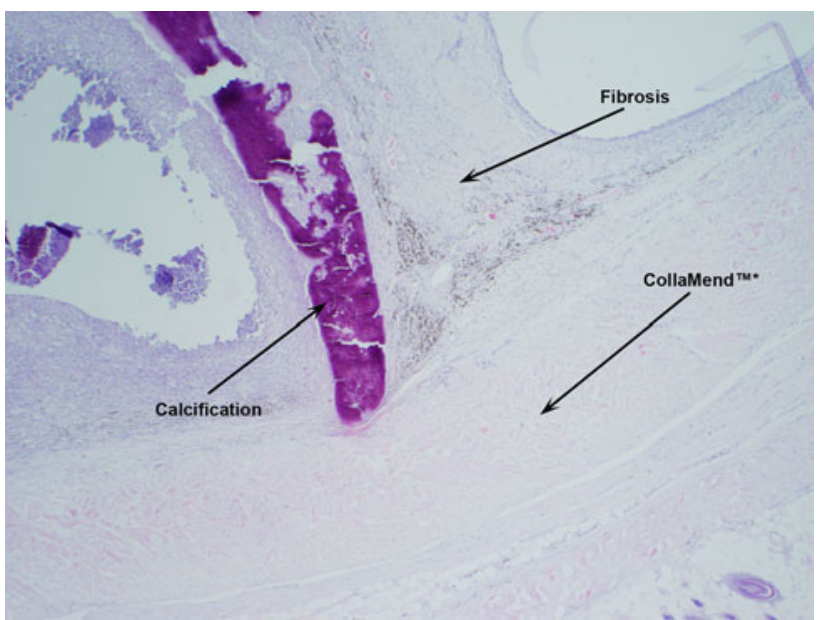

Fig. 7 Calcified tissue adjacent to a CollaMend ${ }^{\mathrm{TM}_{*}}$ implant 6 months after implantation $(H \& E, \times 20)$

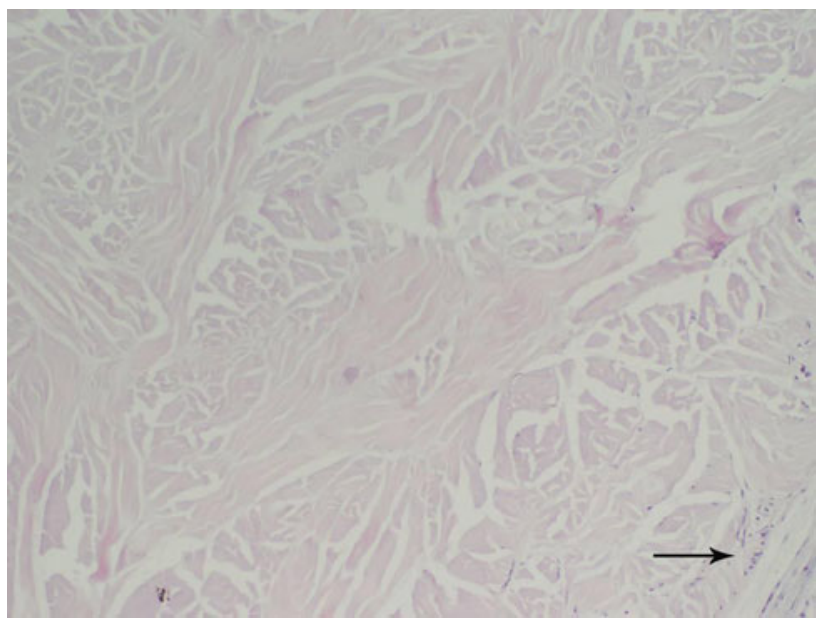

Fig. 8 Permacol $^{\mathrm{TM}}$ implant, 6 months post-implantation with low level of cellular density. Cells are observed mainly at the edges of the implant (arrow) $(\mathrm{H} \& \mathrm{E}, \times 100)$

to marginal levels, leaving implants almost cell free (Fig. 8). Independent of the number of cells within the matrix, integration with host tissue was minimal. Mild levels of mineralisation were observed in the centre of three implants, cellular response was not observed in such areas.

Figure 9 shows the semi-quantitative histometric results for groups at all time points.

\section{Discussion}

Ventral hernia repair remains one of the most common surgical procedures. However, results from ventral hernia repair are less than optimal, with recurrence rates of $12.3 \%$ at 5 years and $23 \%$ at 13 years [39]. Currently, numerous 

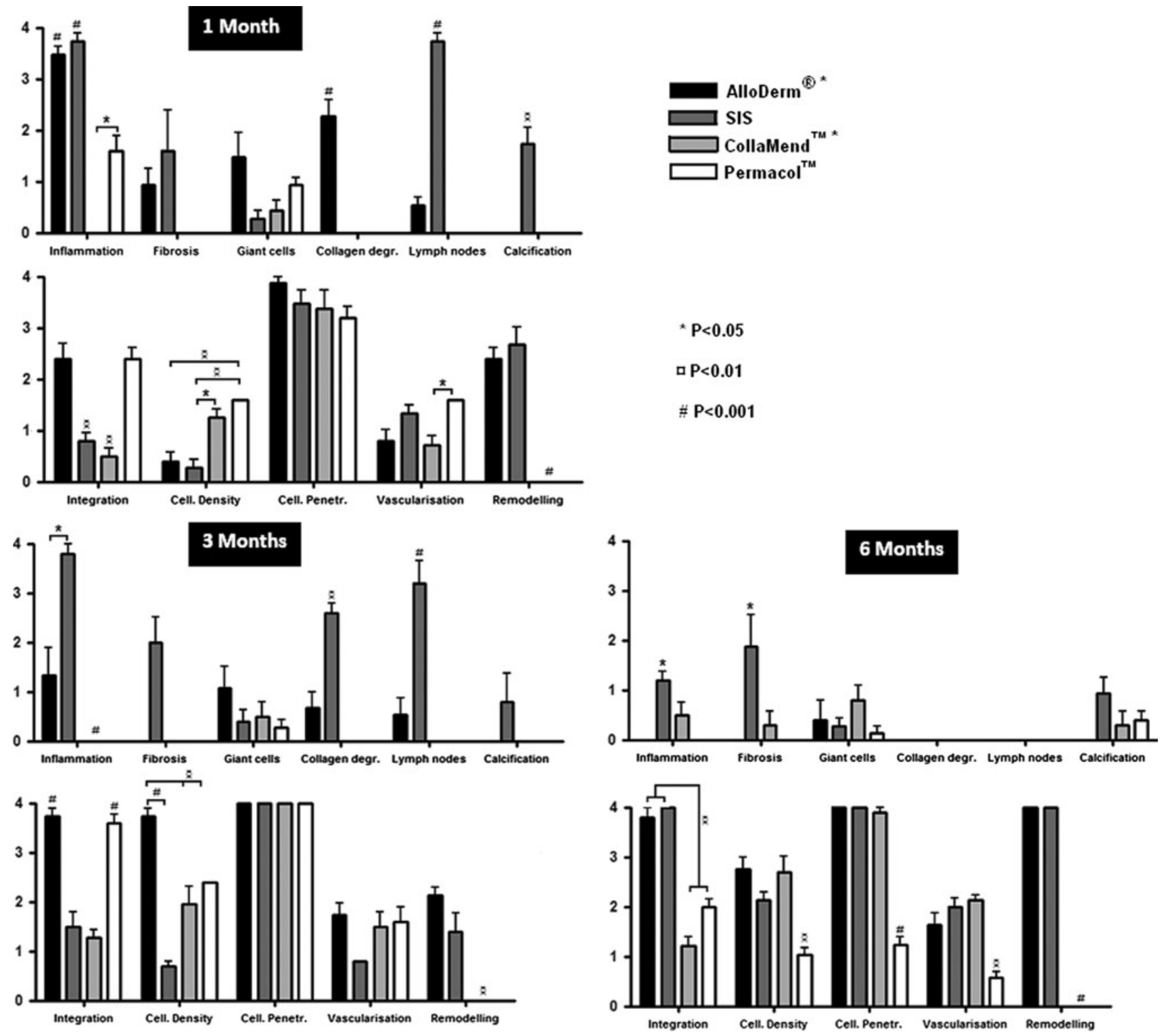

Fig. 9 Histometric results for 1, 3 and 6 months post implantation (mean and SEM)

bioprostheses are available in the surgical field. Their potential benefits include a reduced tendency towards infection compared to synthetic materials, increased biocompatibility, and lowered host foreign-body responses. There are several types of acellular biologic prostheses used clinically for hernia repair and these are characterised mainly by their animal source and applied treatments. This study investigated four commercially available biologic prostheses recommended by manufacturers as being effective in abdominal wall hernia repair: AlloDerm ${ }^{\circledR *}-a$ non-crosslinked human derived mesh, Surgisis Gold ${ }^{\mathrm{TM}}$ - a non-crosslinked porcine derived small intestinal submucosa, CollaMend ${ }^{\mathrm{TM}_{*}}$ and Permacol ${ }^{\mathrm{TM}}$ - two crosslinked porcine derived biological meshes.
Histology of pre-implanted meshes showed acellular matrices for AlloDerm ${ }^{\circledR *}$, CollaMend ${ }^{\mathrm{TM}} *$ and Permacol $^{\mathrm{TM}}$. SIS showed evidence of nuclear material, which may explain the severe inflammatory and immune responses observed post-implantation. The non-crosslinked meshes (AlloDerm ${ }^{\circledR *}$ and SIS) were structurally different from the crosslinked meshes. The latter showed more organised and compact collagen fibres with a particular spatial orientation, strongly contrasting to the interlinked collagen mesh observed in the non-crosslinked collagen matrices, which reflects the different anatomical locations of the source material.

Tensiometry results for AlloDerm ${ }^{\circledR *}$ showed high maximum load values at 1 month post implantation; these 
decreased with time although there was no significant difference between the time-points tested. The moderateto-severe inflammatory response observed may have affected the tensiometry results at 1 month. The increase in the maximum load value from 3 to 6 months suggests an increase in the level of integration, which is corroborated by the histological analysis. It is important to note that stretching of AlloDerm ${ }^{\circledR *}$ was observed in all implants throughout tensiometry analysis. Values for maximum load sustained by SIS implants were similar at both 1 and 3 months; however, due to implant absorption, at 6 months there was not enough implant present to perform tensiometry. Remodelling and absorption of non-crosslinked meshes have been described previously to occur by 4-6 months post implantation [30-32].

Macroscopic observation of CollaMend ${ }^{\mathrm{TM}} *$ samples during tensiometry testing indicated that integration with the surrounding tissue was low; these findings were confirmed later by histopathology analysis. Permacol ${ }^{\mathrm{TM}}$ maximum load results differed significantly different from those of CollaMend ${ }^{\mathrm{TM}_{*}}$ at 1 month post implantation but, although Permacol ${ }^{\mathrm{TM}}$ sustained higher loads at 3 and 6 months compared to all other matrices, this was not statistically significant. Integration of Permacol ${ }^{\mathrm{TM}}$ with the host tissue increased with time; this result was observed both with the tensiometry and histopathological analysis.

The physical and mechanical properties of Coll$\mathrm{aMend}^{\mathrm{TM}} *$ interfered with the study model assessed. The folding of the implant caused discomfort to the animals and eventually exposure of the implant. As previously reported, one animal had to be sacrificed as a result of an open wound caused by friction between the implant and the skin. This caused a moderate suppurative inflammation as a result of infection by bacteria. The bacteria seemed to have a remodelling effect within the CollaMend ${ }^{\mathrm{TM}} *$ matrix, though the collagen was not degraded. This observation questions the durability of CollaMend ${ }^{\mathrm{TM}_{*}}$, particularly in complex environments such as contaminated wounds. Similar results were obtained from animals that were sacrificed as a result of seroma development and subsequent open wounds.

The marketing literature for the devices studied claims host acceptance and strong repair of soft tissue defects. The host response in the present study showed that there were differences in the amount and temporal appearance of inflammatory cells and the morphologic structural integrity of the meshes over time. AlloDerm ${ }^{{ }^{\circledR *}}$ was associated with moderate-to-severe suppurative acute and chronic inflammatory reactions at 1 month post implantation, consisting of an exudate rich in polymorphonucleocytes (PMNs) and lower numbers of mononucleocytes. Fibrotic activity was also observed at this time point, with a high concentration of fibrin surrounding the implants. Inflammation diminished over the study period and was completely resolved at 6 months. The PMN infiltration was resolved at 3 months but macrophages and giant cell numbers were maintained, decreasing at 6 months. These results are in accordance with a study performed by Gaertner and coworkers [9] where they tested AlloDerm ${ }^{\circledR *}$ for ventral hernia repair and reported minimal inflammation up to 3 months post implantation. SIS showed the most severe and long lasting inflammatory and immune responses. In addition, implant delamination, necrosis, fibrosis and mineralisation were also observed at all time points. Another worrying feature observed with SIS implants was the induction of seroma to the point of necessary termination of some of the study subjects; this was matched only by the CollaMend ${ }^{\mathrm{TM}_{*}}$ groups, where animals with seroma chewed through the skin. However, in contrast to the SIS implants, CollaMend ${ }^{\mathrm{TM}_{*}}$ showed no evidence of inflammation in the implants that reached their planned sacrifice date. Similarly, the level of inflammation observed in the Permacol $^{\mathrm{TM}}$ group at 1 month was low and completely resolved by 3 months.

The most concerning clinical feature observed was the enlargement and activation of lymph nodes in both the AlloDerm $^{\circledR *}$ and SIS implants. This indicates a significant host immune response to the implant. Such an effect can pose a problem, especially in challenging clinical fields such as contaminated wounds. Biological meshes should not induce intense inflammatory reactions as this may impair the function of local host tissue defences by reducing leukocyte ability to opsonise and phagocytise bacteria.

Cellular density was high at 1 month in the non-crosslinked meshes, due mainly to the severe inflammatory reactions observed. CollaMend ${ }^{\mathrm{TM}} *$ and Permacol $^{\mathrm{TM}}$ showed minimal numbers of fibroblasts invading the implants at this time point. Cellular density increased for all matrices at 3 months and for CollaMend ${ }^{\mathrm{TM}} *$ and SIS at 6 months. The reduction in cellular presence between 3 and 6 months observed in AlloDerm ${ }^{\circledR *}$ and Permacol ${ }^{\mathrm{TM}}$ was intriguing. Although at 6 months both matrices showed a decrease in cellular infiltration (slight in the case of AlloDerm $^{\circledR *}$ and pronounced in Permacol ${ }^{\mathrm{TM}}$ ), tissue integration with the immediately adjacent host tissue was maintained. These results imply that a constant high number of cells is not necessary for good implant/tissue integration. Cellular ingrowth failure in Permacol ${ }^{\mathrm{TM}}$ implants has been reported by other authors [33, 34], and crosslinking was suggested as one of the causes for the paucity of cellular penetration and cellular density. However, in this study, independent of the number of cells present, cells penetrated through the full depth of the implant, in all implant types, at both 3 and 6 months. This result is in contrast to that obtained in a study performed by Eberli and colleagues, where they 
tested acellular human dermis in a rabbit hernia repair model [35]. They reported that, regardless of a rapid infiltration of host cells from the edges of the implant, the central regions of AlloDerm ${ }^{\circledR *}$ remained free of cells for more than 3 months; this difference in results suggests that the cellular response to AlloDerm ${ }^{(*)}$ may be species-specific or variable due to product variability.

A review of the literature revealed contradictory outcomes when using AlloDerm ${ }^{\circledR *}$ for abdominal wall reconstruction. While some authors reported no complications, others reported a wide range of mesh-associated problems. Buinewicz and Rosen [17] used AlloDerm ${ }^{\circledR *}$ to repair ventral hernias in 44 patients (mean follow-up 20 months), 8 of whom had previous wound infections, and reported no complications or postoperative wound infections. Patton and colleagues [18] performed abdominal wall reconstruction with AlloDerm ${ }^{\mathbb{B}^{*}}$ in 67 patients, with an average follow up of 10.6 months, and reported $18 \%$ recurrent hernias (12 patients), 11 patients had wound infection, 2 patients needed mesh removal, 3 patients developed seroma and 3 patients developed fistulas. Similarly, Gupta and colleagues reported a clinical study with 33 patients using AlloDerm ${ }^{\circledR *}$ to repair ventral hernias, with a follow up of 18 months; they observed $24 \%$ of hernia recurrence, $6 \%$ seroma development and $45 \%$ of diastasis or bulging of muscle [21]. In the same study, Surgisis Gold ${ }^{\mathrm{TM}}$ was used in 41 patients, and there were no hernia recurrences with a mean follow-up of approximately 29 months [21]. Interestingly, when using non-perforated Surgisis mesh, the authors reported significant seroma formation (91\% patients). Seroma complications were not eliminated with the use of perforated Surgisis but were reduced (23\%). Eight of the patients with seroma had their wound re-explored, and of these, five had their mesh explanted. In all of these, the hernia repair was found intact and there were no hernia recurrence. In contrast, Helton and colleagues reviewed 53 patients in whom Surgisis Gold ${ }^{\mathrm{TM}}$ was used in abdominal wall surgery, and reported hernia recurrence (17\%), mesh or wound infection (11\%), partial dehiscence of the wound (21\%), with a total of 22 patients (41\%) sustaining one or more postoperative complication [6].

To the authors' best knowledge there is only one published account of the performance of CollaMend ${ }^{\mathrm{TM}_{*}}$ in humans. Chavarriaga et al. [28] reported a study where 18 patients underwent abdominal wall reconstruction with CollaMend $^{\mathrm{TM}} *$; they reported a recurrence rate of $44.4 \%$. In addition, a total of approximately $39 \%$ of patients developed post operative wounds complications, including infection. Patients with infection had to have the prostheses removed due to encapsulation of the implant rather than incorporation. In our in vivo study, integration in the CollaMend $^{\mathrm{TM}_{*}}$ groups was always greater on the side implanted facing the skin, whereas the CollaMend ${ }^{\mathrm{TM}} *$ side opposed to the peritoneal wall had low integration. This result questions the efficiency of CollaMend ${ }^{\mathrm{TM}} *$ when used as a hernia repair biomaterial, since lack of integration with muscle decreases the healing rate and does not provide tissue support for hernia healing. Poor tissue integration and the adverse tissue reactions observed may explain, in part, post operative wound complications.

Like AlloDerm ${ }^{\circledR *}$, Permacol ${ }^{\mathrm{TM}}$ surgical implant has been occasionally associated with post-surgery complications when used in abdominal wall reconstruction but in other cases surgeons reported uneventful recoveries. When faced with complicated incisional hernias with contamination, Catena and co-workers [36] used Permacol ${ }^{\mathrm{TM}}$ for hernia repair in seven patients and reported no recurrence or wound infection post surgery; the mean follow up was 11 months. Shaikh and colleagues [37] used Permacol ${ }^{\mathrm{TM}}$ in 8 patients for reconstruction of acute abdominal wall defects and in 12 patients with chronic abdominal wall defects; $16 \%$ had an uneventful recovery while 2 patients developed seroma, there were 3 hernia recurrences, 2 patients developed wound infection, 1 patient had a wound hematoma, 1 patient had a wound dehiscence and 1 patient developed a wound sinus.

A marked difference between the morphologic structural integrity of the analysed prosthetic materials was observed. Macrophages and multinucleated giant cells were present in higher numbers following an inflammatory response in the AlloDerm ${ }^{\circledR *}$ groups and at lower numbers in the other matrices. Whilst AlloDerm ${ }^{\circledR *}$ and SIS collagenous matrices showed degradation, at 1 and 3 months, respectively, the crosslinked prostheses did not, except for very low levels of collagen degradation in group $\mathrm{C}_{6 \mathrm{M}}$ when a localized chronic inflammatory response was present. This response was related to the presence of giant cells but the remaining areas of the implant were not degraded or remodelled. The opposite was observed in AlloDerm ${ }^{\circledR *}$ and SIS implants. When inflammatory cells were present, the non-crosslinked matrices were remodelled, losing their initial structure and assuming a configuration where fibres were orientated spatially. Also, AlloDerm ${ }^{\circledR *}$ implant presence decreased with time, and matrix absorption was even more evident in SIS implants. Although AlloDerm ${ }^{\circledR *}$ and SIS were degraded at earlier stages of implantation; neo-collagenesis occurred and new collagen was produced to replace the implant. In contrast, CollaMend $^{\mathrm{TM} *}$ and Permacol ${ }^{\mathrm{TM}}$ were not remodelled and, during the period of this study, matrix absorption was not reported. Such a difference is most likely a result of crosslinking, which should increase the material's resistance to proteolytic activity and explain the durability of these materials in long-term studies. However, in the Permacol ${ }^{\mathrm{TM}}$ groups, implant integration with the surrounding tissue was of good quality and strength, indicating that rapid matrix resorption is not a prerequisite for hernia repair with biologics. 
Marginal mineralisation was observed in the centre of some Permacol ${ }^{\mathrm{TM}}$ implants at 6 months, and calcification, which was associated with fibrosis, was observed in one CollaMend $^{\mathrm{TM}} *$ implant, also at 6 months. In the latter, integration with the host tissue was low and may be explained by the fibrotic mass found between the implant and the peritoneal wall, which decreased the contact area between the implant and the adjacent tissue. Permacol ${ }^{\mathrm{TM}}$ mineralisation has been reported before by Kelley and colleagues [38], who reported dystrophic calcification and bone formation in Permacol ${ }^{\mathrm{TM}}$ implants at 12 months post subcutaneous implantation in mice. Crosslinking was suggested as the cause of the presence of mineralisation. This study suggests otherwise, since SIS implants, a noncrosslinked matrix, showed mineralisation as early as 1 month post implantation, and this feature was observed throughout the study. Although the cause of implant mineralisation is still unknown, based on our results, we suggest that crosslinking is not the factor, or at least is not the only factor, contributing to implant mineralisation. Further studies are needed to explain why mineralisation occurs and the time-frames of such episodes. It is important to note that the presence of mineralised matrix did not appear to be detrimental to the performance of Permacol $^{\mathrm{TM}}$; integration with the host tissue was at the same level as observed in non-mineralised Permacol ${ }^{\mathrm{TM}}$ matrices at the same time-point. Moreover, no inflammatory or immune response was evident in these implants.

The control defects showed a very good rate of healing throughout the study. The control tissue observed 1 month post implantation showed herniation but with good rate of neocollagenesis and tissue reconstruction was already visible. This was further accentuated at 3 months, where the ECM was structurally organised. Finally, at 6 months post implantation, herniation was absent and the defect area was not identifiable. It is important to keep in mind that this was a rodent model and although animals were individually caged, the cage space does not allow them to perform much physical activity, which probably helped the healing of the hernia.

Regarding technical limitations, the chosen model does not consider the risk of adhesion formation. This is an important parameter when evaluating the use of meshes in hernia repair and further studies should comprise full peritoneal defects for a more complete assessment and comparison of bioprostheses performance in abdominal wall repair.

\section{Conclusion}

Experimental investigations in biologic prosthetic materials are important as adverse effects and unfavourable properties of these materials have been demonstrated in laboratory trials. Some of the complications that have occurred clinically may be due to the use of unsuitable materials.

In the rodent model reported here AlloDerm ${ }^{\circledR *}$ and Surgisis Gold ${ }^{\mathrm{TM}}$ showed tissue reactivity with the host; therefore, caution is advised when using these matrices for tissue reconstruction in critically ill patients. Furthermore, the rapid rate of remodelling and degradation of the noncrosslinked matrices may bring further problems in the clinical setting when the overall quality and strength of the newly formed tissue is insufficient for abdominal wall repair, especially where bacterial contamination, which will increase tissue degradation, is suspected. Nevertheless, subjects implanted with non-crosslinked matrices that overcome the initial complications, and reached 6 months post implantation, showed a healed hernia. In the study reported here, due to its physical and biological properties, CollaMend $^{\mathrm{TM}} *$ Implant proved to be unsuitable for hernia repair under the conditions tested. Permacol ${ }^{\mathrm{TM}}$ biological implant integration with the host tissue increased over time, supporting hernia healing with sufficient strength of tissue. It appears to be a safe prosthetic material for ventral hernia repair based on the results of this rodent study.

Acknowledgments This work was funded by Tissue Science Laboratories Limited, a Covidien group company.

Open Access This article is distributed under the terms of the Creative Commons Attribution Noncommercial License which permits any noncommercial use, distribution, and reproduction in any medium, provided the original author(s) and source are credited.

\section{References}

1. Burger JW, Luijendijk RW, Hop WC, Halm JA, Verdaasdonk EG, Jeekel J (2004) Long-term follow-up of a randomized controlled trial of suture versus mesh repair of incisional hernia. Ann Surg 240(4):578-583

2. Saettele TM, Bachman SL, Costello CR, Grant SA, Cleveland DS, Loy TS, Kolder DG, Ramshaw BJ (2007) Use of porcine dermal collagen as a prosthetic mesh in a contaminated field for ventral hernia repair: a case report. Hernia 11(3):279-285

3. Catena F, Ansaloni L, Gazzotti F, Gagliardi S, Di SS, D'Alessandro L, Pinna AD (2007) Use of porcine dermal collagen graft (Permacol) for hernia repair in contaminated fields. Hernia 11(1):57-60

4. Hammond TM, Chin-Aleong J, Navsaria H, Williams NS (2008) Human in vivo cellular response to a cross-linked acellular collagen implant. Br J Surg 95(4):438-446

5. Stoppa R (2003) About biomaterials and how they work in groin hernia repairs. Hernia 7(2):57-60

6. Helton WS, Fisichella PM, Berger R, Horgan S, Espat NJ, Abcarian $\mathrm{H}$ (2005) Short-term outcomes with small intestinal submucosa for ventral abdominal hernia. Arch Surg 140(6):549-560

7. Liyanage S, Purohit G, Frye J, Giordano P (2006) Anterior abdominal wall reconstruction with a Permacol implant. J Plast Reconstr Aesthet Surg 59:553-555 
8. Parker D, Armstrong P, Frizzi J, North J Jr (2006) Porcine dermal collagen (Permacol) for abdominal wall reconstruction. Curr Surg 63(4):255-258

9. Gaertner W, Bonsak M, Delaney J (2007) Experimental evaluation of four biologic prostheses for ventral hernia repair. J Gastrointest Surg 11(10): 1275-1285

10. Smart NJ, Mercer-Jones MA (2007) Functional outcome after transperineal rectocele repair with porcine dermal collagen implant. Dis Colon Rectum 50(9):1422-1427

11. Harper C (2001) Permacol: clinical experience with a new biomaterial. Hosp Med 62(2)

12. Khor E (1997) Methods for the treatment of collagenous tissues for bioprostheses-review. Biomaterials 18:95-105

13. Hammond TM, Chin-Aleong J, Navsaria H, Williams NS (2008) Human in vivo cellular response to a cross-linked acellular collagen implant. Br J Surg 95(4):438-446

14. Hiles M, Record Ritchie RD, Altizer AM (2009) Are biologic grafts effective for hernia repair?: a systematic review of the literature. Surg Innov 16(1):26-37

15. Hsu PW, Salgado CJ, Kent K, Finnegan M, Pello M, Simons R, Atabek U, Kann B (2009) Evaluation of porcine dermal collagen (Permacol) used in abdominal wall reconstruction. J Plast Reconstr Aesthet Surg 62(11):1484-1489

16. Shaikh FM, Giri SK, Durrani S, Waldron D, Grace PA (2007) Experience with porcine acellular dermal collagen implant in one-stage tension-free reconstruction of acute and chronic abdominal wall defects. World J Surg 31(10):1966-1972

17. Buinewicz B, Rosen B (2004) Acellular cadaveric dermis (AlloDerm): a new alternative for abdominal hernia repair. Ann Plast Surg 52(2):188-194

18. Patton J, Berry S, Kralovich K (2007) Use of human acellular dermal matrix in complex and contaminated abdominal wall reconstruction. Am J Surg 193:360-363

19. Kolker AR, Brown DJ, Redstone JS, Scarpinato VM, Wallack MK (2005) Multilayer reconstruction of abdominal wall defects with acellular dermal allograft (AlloDerm) and component separation. Ann Plast Surgery 55(1):36-41

20. Hirsch E (2004) Repair of an abdominal wall defect after a salvage laparotomy for sepsis. J Am Coll Surg 198(2):324-328

21. Gupta A, Zahriya K, Mullens P, Salmassi S, Keshishian A (2006) Ventral herniorrhaphy: experience with two different biosynthetic mesh materials, Surgisis and AlloDerm. Hernia 10:419-425

22. Badylak S, Kokini K, Tullius B, Whitson B (2001) Strength over time of a resorbable bioscaffold for body wall repair in a dog model. J Surg Res 99(2):282-287

23. Badylak SF (2002) The extracellular matrix as a scaffold for tissue reconstruction. Semin Cell Dev Biol 13(5):377-383

24. Hodde J (2002) Naturally occurring scaffolds for soft tissue repair and regeneration. Tissue Eng 8(2):295-308

25. Ansaloni L, Catena F, D’Alessandro L (2003) Prospective randomized, double-blind, controlled trial comparing Lichtenstein's repair of inguinal hernia with polypropylene mesh versus Surgisis gold soft tissue graft: preliminary results. Acta Biomed 74(2):10-14

26. Catena F, Ansaloni L, Leone A, De CA, Gagliardi S, Gazzotti F, Peruzzi S, Agrusti S, D’Alessandro L, Taffurelli M (2005) Lichtenstein repair of inguinal hernia with Surgisis inguinal hernia matrix soft-tissue graft in immunodepressed patients. Hernia 9(1):29-31

27. Fine AP (2006) Laparoscopic repair of inguinal hernia using Surgisis mesh and fibrin sealant. JSLS 10(4):461-465

28. Chavarriaga LF, Lin E, Losken A, Cook MW, Jeansonne LO, White BC, Sweeney JF, Galloway JR, Davis SS Jr (2010) Management of complex abdominal wall defects using acellular porcine dermal collagen. Am Surg 76(1):96-100

29. Petter-Puchner AH, Fortelny RH, Mittermayr R, Walder N, Ohlinger W, Redl H (2006) Adverse effects of porcine small intestine submucosa implants in experimental ventral hernia repair. Surg Endosc 20(6):942-946

30. Chaplin JM, Costantino PD, Wolpoe ME, Bederson JB, Griffey ES, Zhang WX (1999) Use of an acellular dermal allograft for dural replacement: an experimental study. Neurosurgery 45(2):320-327

31. Tarhan E, Cakmak O, Ozdemir BH, Akdogan V, Suren D (2008) Comparison of AlloDerm, fat, fascia, cartilage, and dermal grafts in rabbits. Arch Facial Plast Surg 10(3):187-193

32. Xu H, Wan H, Sandor M, Qi S, Ervin F, Harper JR, Silverman RP, McQuillan DJ (2008) Host response to human acellular dermal matrix transplantation in a primate model of abdominal wall repair. Tissue Eng A 14(12):2009-2019

33. MacLeod T, Williams G, Sanders R, Green C (2005) Histological evaluation of Permacol as a subcutaneous implant over a 20-week period in the rat model. Br J Plast Surg 58:518-532

34. Valentin JE, Badylak JS, McCabe GP, Badylak SF (2006) Extracellular matrix bioscaffolds for orthopaedic applications. A comparative histologic study. J Bone Joint Surg 88(12):2673-2686

35. Eberli D, Rodriguez S, Atala A, Yoo JJ (2010) In vivo evaluation of acellular human dermis for abdominal wall repair. J Biomed Mater Res A 93(4):1527-1538

36. Catena F, Ansaloni L, Gazzotti F, Gagliardi S, Di SS, D’Alessandro L, Pinna AD (2007) Use of porcine dermal collagen graft (Permacol) for hernia repair in contaminated fields. Hernia 11(1):57-60

37. Shaikh FM, Giri SK, Durrani S, Waldron D, Grace PA (2007) Experience with porcine acellular dermal collagen implant in one-stage tension-free reconstruction of acute and chronic abdominal wall defects. World J Surg 31(10):1966-1972

38. Kelley P, Gordley K, Higuera S, Hicks J, Hollier L (2005) Assessing the long-term retention and permanency of acellular cross-linked porcine dermal collagen as a soft-tissue substitute. Plast Reconstr Surg 116(6):1780-1784

39. Flum DR, Horvath K, Koepsell T (2003) Have outcomes of incisional hernia repair improved with time? A population-based analysis. Ann Surg 237:129-135 